observations show that this coagulation is due to the presence of an enzyme in goat semen. The enzyme is present in plasma and requires activation by ealcium; hence absence or delay of coagulation of medium containing citrate. Hurther, when sperm. atozoa are freed from this enzyme, by washing with normal saline, viability is greatly improved.

(1) Washed spermatozoa remain vigorously motile for 6 and 9 days in egg yolk citrate and glycine egg yolk respectively at $3^{\circ} \mathrm{C}$., whereas when neat semen was used the life of sperms was 3 days only. Whereas extinction of the spermatozoal life was preceded by complete coagulation or curdling of glycine egg yolk, no such physical change took place either in the other diluent egg yolk citrate or in control tubes containing glycine egg yolk only. With 'sperm free-plasma' complete coagulation of glycine egg yolk took place within 2 days at $3^{\circ} \mathrm{C}$. and in about $10 \mathrm{hr}$. when incubated at $37^{\circ} \mathrm{C}$. Coagulation, however, did not take place at $3^{\circ} \mathrm{C}$. when such plasma was added to glycine egg yolk after being treated for $2 \mathrm{~min}$. in a boiling water-bath.

Later it was found that coagulation also took place when, instead of glycine egg yolk, a mixture of equal volumes of water and egg yolk is used. In all subsequent experiments egg yolk and water mixed in the proportion of $4: 1$ was used as the substrate.

Since serninal plasma is made up of the secretions of the seminal vesicle, prostate and Cowper's gland, it is obvious that the source of this enzyme must be one of these glands. These organs were dissected immediately after slaughter of adult goats and were extracted with cold distilled water by triturating them separately in mortars with sand; for every gram of the material $10 \mathrm{ml}$. of water was used. The extracted material was then centrifuged for $20 \mathrm{~min}$.

(2) When $0.5 \mathrm{ml}$. of the supernatant was added to $2 \mathrm{ml}$. of substrate it was found that coagulation of egg yolk took place only with Cowper's gland extract and not with the extracts of the other two glands. The time required for coagulation varied between 24 and $30 \mathrm{hr}$. at $3^{\circ} \mathrm{C}$. and between 2 and $3 \mathrm{hr}$. at $37^{\circ} \mathrm{C}$. Aliquots of Cowper's gland extract when used after being kept in a boiling water-bath for $2 \mathrm{~min}$. was always ineffective in bringing about coagulation. Extracts preserved in a refrigerator with a drop of chloroform in them have been found to retain the coagulating activity in full for more than 6 weeks. The extract has been found to be incapable of bringing about coagulation of either egg white, or mixture of egg white and egg yolk, or milk. Egg yolk therefore appears to be the specific substrate of this coagulating enzyme. Extracts made out of the Cowper's gland obtained from castrated goats are conspicuous in not possessing any coagulating activity. It appears, therefore, that the elaboration of the egg yolk-coagulating enzyme in Cowper's gland is dependent on the male hormone testosterone. The eoagulating effect is also absent in extracts made out of Cowper's gland obtained from an adult ram. The time required for coagulation of egg yolk, either by seminal plasma or Cowper's gland extract, is prolonged when citrate or oxalate is added to the medium.

Investigations to study the various characteristics of this enzyme are in progress.

College of Veterinary Science

A. Roy

and Animal Husbandry,

Mathura, India.

Nov. 15.

\section{Sensitivity of the Mouse Mamma to Urinary Mammotrophin}

Ir has recently been shown that mammotrophic hormones are present in the urine of an appreciable number of pre- and post-menopausal women ${ }^{1}$. These hormones are capable of stimulating growth in the mammary glands of weanling male mice. It has been found, however, that different strains of mice react unequally to the same known stimulus and some fail to respond at all.

Many strains of laboratory mice, including the wellknown $A, C 57 B l, C_{3} H, D B A, B A L B$ and $L A B$ Grey, have been investigated for mammary sensit. ivity. Ten male weanlings were used from each strain ; they were injected twice daily for five days with a human urine proved to be active in a reacting strain of mouse. On the sixth day the animals were killed and skinned. The pelts were fixed and afterwards stained. The anterior six glands were dissected off, cleared and mounted.

Reacting glands are characterized by bulbous swellings (called 'clubs') at the ends of the ducts. The average number of clubs per gland is determined for all the glands in a given strain of mouse. This 'club count' is considered to be a measure of the degree of the reaction. No urine was considered 'active' unless on injection it stimulated our standard reactive mouse and produced an average club count of 3.5 per gland or more.

Contrary to expectation, it was found that the ability to react to mammotrophins is an uncommon property among mice. So far, only one inbred strain $\left(A_{2} G\right)$ and one non-inbred strain (S.A.S. 3) have been found to possess it to a significant degree. A full account of this work is in course of preparation for publication elsewhere.

These striking variations in mammary reactivity are of great practical significance, as the estimation of mammotrophic potency of the urine is becoming an important pre-operative test in cases of human breast cancer treated by hypophysectomy.

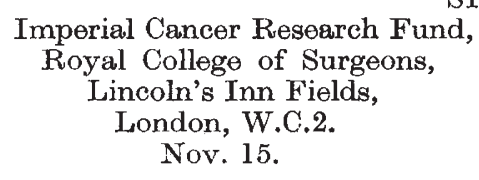
STRETTON YOUNG

Hadfleld, G., and Young, J. Stretton, Brit. J. Cancer, 10, 324 (1956).

\section{Reversibility of Fluorescence by Annealing}

Some time ago, Ewles et al. ${ }^{1}$ found that a large number of colourless inorganic solids show, on excitation by light of wave-length shorter than 330 $\mathrm{m} \mu$, a bluish fluorescence (and phosphorescence) when wetted by distilled water.

While studying the fluorescence of various minerals, I found that a bluish-greenish fluorescence shown by many of them when excited by ultra-violet light of wave-length $365 \mathrm{~m} \mu$ is also due to adsorbed water. The fluorescence does not appear after the samples have been strongly heated for a short time, but it returns when they are either kept for months exposed to the air or when they are wetted. Rather surprisingly, the fluorescence is also regenerated when the strongly heated samples are heated again to a less degree, an effect which can be referred to as 'fluorescence, reversible by annealing'. 